\title{
西藏地区现代沉积物中介形类环境指示意义初探"
}

\author{
宋 高 $^{1}$, 王海雷 ${ }^{1 * *}$, 郑绵平 ${ }^{1}$, 李 军 $^{2}$ \\ (1: 中国地质科学院矿产资源研究所, 国土资源部盐湖资源与环境重点实验室,北京 100037) \\ (2: 四川大学建筑与环境学院, 成都 610065)
}

摘 要: 于 2008 和 2012 年先后 2 次从西藏阿里和那曲地区 61 个不同水体,包括不同盐度的湖泊、湿地、浅水坑和河流 等, 共采集了 78 个水体表层沉积物样品, 用以研究该地区现生介形类的生态分布及其环境指示意义. 经鉴定, 阿里和那 曲地区现生介形类共计 11 属 38 种. 除 Ilyocypris neoaspera 等 5 个种外, 本次调查的介形类各属种均在湖泊中出现, 尤以 Limnocythere dubiosa 的总壳瓣数最为丰富. Ilyocypris 属中除 Ilyocypris subdunshanensis 和 Ilyocypris xizangensis 外, 其余各种 均喜浅水坑的小型浅水环境. Leucocythere dilitata、Limnocythere dubiosa、Limnocytherellina kunlunensis 和 Eucypris rischtanica 为该地区的广盐种. 其中 Limnocythere dubiosa 和 Leucocythere dilitata 适应盐度范围最广, 在不同盐度的各类水体中均有 出现. 本次研究中的介形类均喜碱性水体, 在 $\mathrm{pH}$ 值为 $8 \sim 9$ 的水体中介形类各属种的丰度值达到最大.

关键词: 现代沉积物; 现生介形类; 生态分布; 西藏地区; 环境指示意义

\section{Preliminary study on environmental implications of ostracodes in modern deposits in Tibet}

\section{SONG Gao ${ }^{1}$, WANG Hailei ${ }^{1}$, ZHENG Mianping ${ }^{1} \&$ LI Jun $^{2}$}

(1: MLR Key Laboratory of Saline Lake Resources and Environment, Institute of Mineral Resources, Chinese Academy of Geological Sciences, Beijing 100037 , P. R. China)

(2: School of Architecture and Environment, Sichuan University, Chengdu 610065, P. R. China)

Abstract: 78 surface sediment samples in 61 different water bodies, such as lakes with different salinities, swamps, shallow puddles and rivers, in Ali and Naqu regions in Tibet, were collected to study the ecological distribution of extant ostracodes and their environmental implications. Total of 11 genus and 38 species living ostracodes are identified. All kinds of ostracodes in this research area are found in lakes except for the Ilyocypris neoaspera and other 4 species, and the number of Limnocythere dubiosa is the most abundant in the lakes. All Ilyocypris species prefers small and shallow water like shallow puddles except I. subdunshanensis and I. xizangensis. Leucocythere dilitata, Limnocythere dubiosa, Limnocytherellina kunlunensis and Eucypris rischtanica are euryhaline species in these regions, among which $L$. dubiosa and $L$. dilitata have the strongest tolerance for salinity and they have been found in a variety of water bodies with different salinities. Ostracodes prefer alkaline water and have the maximum abundance in water bodies with $\mathrm{pH}$ values of $8-9$.

Keywords: Modern deposits; extant ostracodes; ecological distribution; Tibet; environmental implications

青藏高原是全球气候变化研究的一个热点. 高原上湖泊众多,其中面积大于 $0.5 \mathrm{~km}^{2}$ 的约有 1612 个 $^{[1]}$. 湖泊沉积物, 尤其是湖泊沉积物中的微体生物对环境变化具有非常敏感的响应, 其中的介形类作为一种重 要的环境指标得到了广泛的研究. 介形虫是一种水生双壳类动物, 在各种自然水体中, 几乎均有介形虫的发 育. 介形虫在生长过程中对环境因子 (尤其是盐度、温度和水动力条件等) 比较敏感 ${ }^{[2]}$, 虫体死亡后壳体与有 机体及宿生水体不再进行物质交换,因此其壳体保存了壳体形成时的环境信息. 同时形成的碳酸钙壳体在

* 国家自然科学基金项目 (41372179)、国土资源部公益性行业专项 (201311140) 和国家地质大调查项目 (12120114048501) 联合资助. 2014-07-09 收稿;2014-12-28 收修改稿. 宋高 (1986 ), 女, 博士研究生; E-mail: songgao1985128@126.com.

** 通信作者;E-mail: wanghailei77@ 126. com. 
沉积环境中易于保存, 不易受后期改造影响, 因此是研究古环境古气候演变很好的材料. 但是目前介形虫属 种的环境指示意义大都还是建立在地层化石的研究基础上,所得出的环境指示意义是根据地层中其它环境 指标相互印证而来的,其环境指示意义不明确且可靠性较低. 近年来有学者开始尝试现生介形虫的调查研 究, 通过与其现生属种生活环境条件的统计分析, 建立介形虫属种与环境条件的相关关系, 并进一步明确其 环境指示意义 ${ }^{[3]}$. 但是目前这种现生介形虫的调查研究在国内还仅限于少数几个区域,如太湖流域 ${ }^{[4]}$ 、青海 湖地区 ${ }^{[5-6]}$ 、贵州地区 ${ }^{[7]}$ 、云南地区 ${ }^{[8-9]}$ 和柴达木盆地 ${ }^{[10]}$ 等. 黄宝仁等 ${ }^{[11]}$ 在西藏地区虽然开展了一些湖泊现 生介形虫的调查, 但没有做详细的分析研究. 最近 Mischke 等 ${ }^{[12]}$ 研究了青藏高原东部现代湖泊介形类的分 布规律, 建立了介形类属种与电导率的定量转换关系,并详细研究了青藏高原东缘冬给错纳湖不同水深的 介形类组合, 建立介形类组合与水深的定量转换关系 ${ }^{[13]}$. 但是这些定量转换关系, 仅限于青藏高原东部地 区, 是否适用于整个青藏高原地区仍需扩大研究范围进一步验证.

本文于 2008 和 2012 年先后 2 次系统调查西藏阿里和那曲地区的众多湖泊、河流等水体,开展现生介形 虫的生态分布研究, 以重新厘定西藏地区现生介形虫属种的环境指示意义, 也为今后进一步的室内培养实 验和基于壳体地球化学的定量环境指示意义的研究奠定基础.

\section{1 材料与方法}

从西藏阿里和那曲地区 61 个不同水体,包括不同盐度的湖泊, 以及湿地、浅水坑和河流等,共采集了 78 个水体表层沉积物样品进行介形类与环境关系的分析研究. 采样点分布见图 1, 详细信息见附表. 采用抓斗 式采泥器采集不同水体的沉积物, 仔细刮取表层 $1 \mathrm{~cm}$ 的沉积物样品, 在室内烘干后称取 $50 \mathrm{~g}$, 用蒸馏水浸泡 并过 200 目篎, 剩余物再烘干, 仔细挑取其中的介形类壳体. 在实验室用光镜对样品进行分拣、鉴定和保存. 属种鉴定主要参考文献[14-15]. 水体盐度及 $\mathrm{pH}$ 值采用 Thermo scientific 测试仪在采样现场测定. 2008 年所 测水体的矿化度以盐度表示, 2012 年所测水体的矿化度用电导率来表示, 为统一划分水体盐度, 根据 1978 年使用盐标公式,采用 MarkIII 型 CTD 系统定标常数,将 2012 年所测水体电导率转化为盐度.

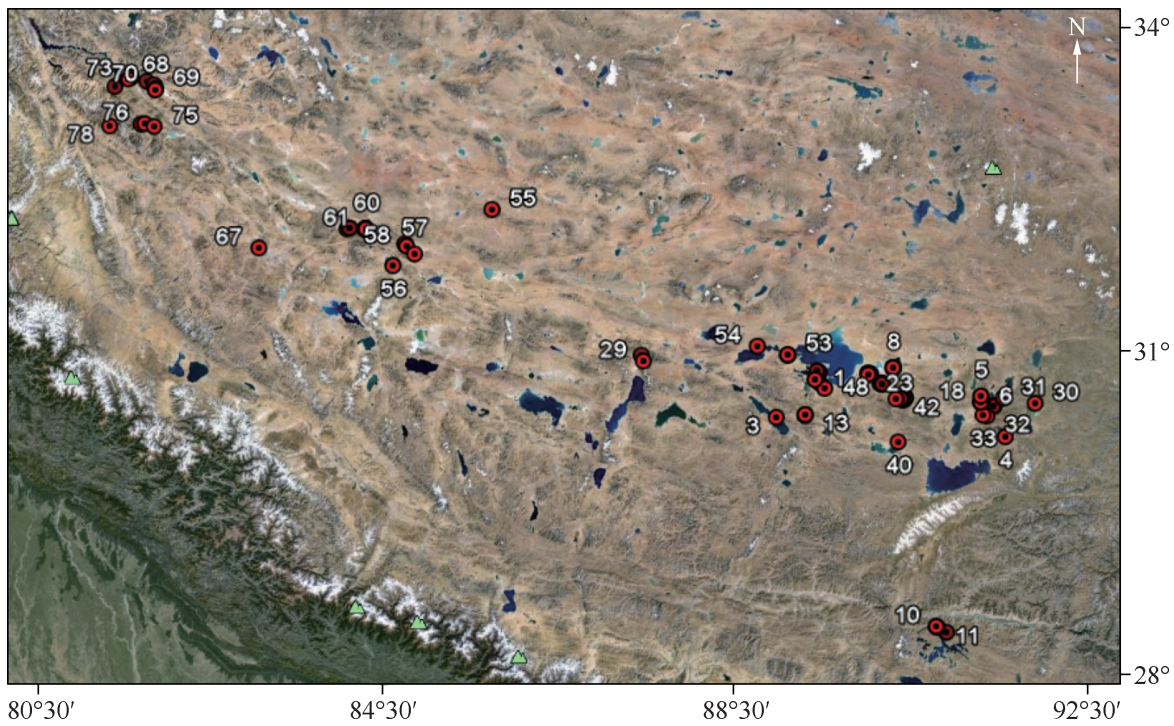

图 1 样品采集位置图

Fig. 1 Sites of sediment samples

在计算介形类各属种出现的频次时,以采集的水体作为计算单位,在该水体任何采样点出现某种介形 类, 即认为该种介形类在该水体出现. 


\section{2 结果}

\section{1 介形类栖息环境分布特征}

介形类生活的环境多种多样, 但其单个属种往往偏爱某些特定的环境, 在这些特定的环境下, 介形类容 易繁殖发育,并达到最大丰度. 本次研究获得大量现生介形类壳体,共计 11 属 38 种(表 1).

表 1 西藏阿里、那曲地区现代沉积物中介形类的分布

Tab. 1 The distribution of ostracodes in the recent sediments in Ali and Naqu regions in Tibet

\begin{tabular}{|c|c|c|c|}
\hline 种类 & 频数 & 产地环境(频数/总壳瓣数) & $\mathrm{pH}$ 值 \\
\hline Leucocythere dorsotuberosa & 5 & 湖泊 (4/99)、河流(1/1) & $6.80 \sim 9.90$ \\
\hline L. dilitata & 9 & 湖泊 $(6 / 18) 、$ 浅水坑 $(1 / 5) 、$ 湿地 $(1 / 5) 、$ 河流 $(1 / 10)$ & $7.20 \sim 9.90$ \\
\hline L. exilitropis & 3 & 湖泊 $(3 / 20)$ & $8.20 \sim 8.60$ \\
\hline L. tropis & 5 & 湖泊 (4/60)、河流 (1/1) & $6.80 \sim 9.70$ \\
\hline L. pseudosculpta & 2 & 湖泊 $(2 / 10)$ & $8.20 \sim 8.60$ \\
\hline L. postericosta & 5 & 湖泊(3/51)、浅水坑(1/90)、河流(1/4) & $8.13 \sim 10.41$ \\
\hline L. mirabilis & 3 & 湖泊(2/2)、浅水坑(1/3) & $8.20 \sim 10.69$ \\
\hline L. subsculpta & 5 & 湖泊(3/6)、湿地 (1/2)、河流(1/16) & $8.20 \sim 10.14$ \\
\hline L. parasculta & 2 & 湖泊(1/2)、浅水坑(1/22) & $8.95 \sim 9.62$ \\
\hline Limnocythere dubiosa & 27 & 湖泊 $(19 / 1956) 、$ 浅水坑 $(6 / 128) 、$ 河流 $(1 / 15) 、$ 湿地 $(1 / 28)$ & $7.20 \sim 11.14$ \\
\hline Limnocytherellina kunlunensis & 8 & 湖泊 (5/423)、河流(2/261)、湿地(1/100) & $7.20 \sim 9.53$ \\
\hline L. bispinosa & 3 & 湖泊(1/15)、河流(1/58)、湿地(1/83) & $6.80 \sim 9.70$ \\
\hline L. trispinosa & 5 & 湖泊(2/46)、河流(2/23)、湿地(1/3) & $6.80 \sim 9.90$ \\
\hline Ilyocypris bradyi & 20 & 湖泊(12/150)、浅水坑(5/343)、河流(3/57) & $6.80 \sim 10.41$ \\
\hline I. tuberculata & 2 & 湖泊(1/8)、浅水坑(1/39) & $7.90 \sim 8.20$ \\
\hline I. dunschanensis & 4 & 湖泊(3/43)、浅水坑(1/35) & $7.30 \sim 9.90$ \\
\hline I. gibba & 2 & 湖泊(1/6)、浅水坑(1/12) & $7.90 \sim 8.20$ \\
\hline I. cornae & 3 & 湖泊 $(2 / 4) 、$ 、浅水坑 $(1 / 29)$ & $7.90 \sim 9.70$ \\
\hline I. subdunshanensis & 1 & 湖泊 $(1 / 3)$ & 8.20 \\
\hline I. neoaspera & 1 & 浅水坑(1/2) & 7.90 \\
\hline I. echinata & 2 & 湖泊(1/28)、浅水坑(1/28) & $8.95 \sim 9.01$ \\
\hline I. xizangensis & 2 & 湖泊 $(2 / 6)$ & $8.22 \sim 9.61$ \\
\hline Candona xizangensis & 1 & 湖泊(1/11) & $8.20 \sim 9.20$ \\
\hline C. houae & 2 & 湖泊(1/13)、浅水坑(1/17) & $8.13 \sim 10.41$ \\
\hline C. lijiangensis & 1 & 湿地 $(1 / 4)$ & 9.70 \\
\hline C. neglecta & 2 & 湖泊 $(2 / 5)$ & $7.20 \sim 9.70$ \\
\hline C. candida & 11 & 湖泊(7/427)、浅水坑(3/136)、河流(1/10) & $8.20 \sim 10.41$ \\
\hline C. rawsoni & 1 & 浅水坑(1/5) & 9.16 \\
\hline Candoniella lactea & 2 & 浅水坑(1/33)、河流(1/16) & $8.64 \sim 9.16$ \\
\hline C. mirabilis & 1 & 湖泊 $(1 / 7)$ & 8.20 \\
\hline C. albicans & 1 & 湖泊 $(1 / 4)$ & 9.70 \\
\hline Eucypris inflata & 2 & 湖泊 $(2 / 193)$ & $9.40 \sim 9.70$ \\
\hline E. rischtanica & 9 & 湖泊 $(6 / 1512) 、$ 河流 (2/256)、浅水坑(1/3) & $6.80 \sim 9.90$ \\
\hline E. zandaensis & 2 & 湖泊(1/3)、浅水坑 (1/1) & $7.90 \sim 8.20$ \\
\hline Prionocypris gansenensis & 1 & 湖泊 $(1 / 1)$ & 9.70 \\
\hline Cypricercus moguntiensis & 2 & 浅水坑(1/1)、湿地(1/1) & $9.01 \sim 9.70$ \\
\hline Heterocypris salinus & 3 & 浅水坑(1/1)、湿地(1/1)、河流(1/16) & $8.64 \sim 9.70$ \\
\hline Cyprideis littoralis & 1 & 湖泊 $(1 / 1)$ & 9.03 \\
\hline
\end{tabular}


介形类属种丰富的水体主要有崩错 (4 属 15 种)、羊卓雍错 YC-3 点位 (6 属 10 种)、班戈湖 BG-2-1 点位 (6 属 10 种)、日土到叶城主道边的小湖 (xz-43 点位, 7 属 11 种) 以及班公错东南岸的湿地 ( xz-45 点位, 6 属 9 种). 丰度最大的分别为夏穷错 XQ-3 点位和班戈湖 BG-4 点位,均达到 730 余枚 $/ 50 \mathrm{~g}$ (附表). 同一个湖泊 的不同采样点之间介形类的分布也有很大差异, 有的点位介形虫的属种数和壳瓣数均很多, 但在有些点位 却没有发现介形虫的壳体. 而同一湖泊不同点位之间在水体理化性质上并无太大区别,盐度变化不大, 且本 次采样各点位的 $\mathrm{pH}$ 值和水深也没有太大的区别, 因此影响介形虫生长分布的可能是不同点位之间的微环 境以及水动力条件和沉积物的岩性等因素.

根据水体的环境,将采集水体分为 4 大类, 即湖泊 (指长期存在, 具有一定面积和深度的水体)、浅水坑 (季节性或短期存在, 较浅且面积较小的水体)、湿地和河流. Limnocythere dubiosa、Limnocytherellina kunlunensis、Ilyocypris bradyi、Candona candida、Eucypris rischtanica 和 Leucocythere dilitata 在 61 个点位中均出现 8 次以 上,为该地区常见种 (表 1). 其中 Limnocythere dubiosa 出现频次达 27 次,为该地区分布最广泛的介形类,在 湖泊、河流、湿地以及浅水坑等环境中都有产出, 又以湖泊环境中出现的频率最高, 达 19 次, 表明 Limnocythere dubiosa 对环境的适应性很强, 是西藏那曲和阿里地区最常见的种. Ilyocypris bradyi 的出现频率仅次于 Limnocythere dubiosa, 在本研究的 20 个点位均有出现, 该种在湖泊中的出现频率最高, 但丰度不大, 在浅水坑中 的出现频率虽不及湖泊, 但其丰度远大于湖泊, 本次研究在湿地中没有发现 Ilyocypris bradyi. Candona candi$d a$ 的出现频数为 11 次, 主要在湖泊、浅水坑及河流的环境中出现,其中湖泊中该种的频数及丰度达到最大. Leucocythere dilitata 的丰度不大, 但出现频率较高, 在 9 个采样水体中均有出现, 分别为湖泊、河流、浅水坑及 湿地, 频率和丰度最大的为湖泊, 其余环境下数量很小. Eucypris rischtanica 的出现频数也为 9 次, 该种在湖 泊、河流和浅水坑中均出现,其中在湖泊环境中出现频率最高,丰度也达到最大,在湿地环境下没有发现该 种. Limnocytherellina kunlunensis 的出现频率不是很大, 但总体丰度较大, 共发现 784 枚壳体, 其中以湖泊中的 出现频率和丰度为首, 远高于河流和湿地环境下的,在浅水坑中没有发现该种.

\section{2 不同盐度水体中介形类的分布特征}

根据 1958 年威尼斯分类法, 我们将本次调查的水体按盐度分为淡水 (含盐量 $<0.5 \%$ ) 、少盐水 (含盐量 为 $0.5 \% \circ \sim 5 \%$ ) 、中盐水 (含盐量为 5\%o 18\%o) 、多盐水 (含盐量为 $18 \% \circ \sim 30 \%$ ) 、真盐水 (含盐量为 30\%o $40 \%$ ) 和超盐水 (含盐量 $>40 \%$ ) 6 类. 从图 2 大致可以归纳出几类适于不同盐度的介形类组合. 淡水介形类 以 Ilyocypris tuberculata、I. gibba、I. echinata 和 Leucocythere parasculta 为主, 另外 Ilyocypris subdunshanensis、I. neoaspera、Candoniella mirabilis 和 Eucypris zandaensis 等也有少量出现. 而 Candona candida 和 Leucocythere exilitropis 等虽在少盐水中也有出现, 但主要的产出水体仍为淡水. Ilyocypris dunschanensis、I. cornae 和 Candona neglecta 等的主要产出水体也为淡水,但在真盐水或超盐水中也有少量分布. Cypricercus moguntiensis、Heterocypris salinus、Leucocythere subsculpta、L. pseudosculpta、L. mirabilis 和 Candona xizangensis 等在淡水和少盐水中 均有分布. 而 Candoniella lactea、Candona rawsoni、C. lijiangensis 和 Cyprideis littoralis 则只在少盐水中有少量 分布. Limnocytherellina trispinosa、L. bispinosa 和Candona houae 主要在少盐水中出现,但在多盐水或超盐水中 也有少量分布. Eucypris inflata 只在多盐水中大量出现. Candoniella albicans、Prionocypris gansenensis 和 Ilyocypris xizangensis 则只在真盐水或超盐水中有少量出现. Leucocythere dorsotuberosa、L. tropis、L. dilitata、L. postericosta、Eucypris rischtanica、Limnocytherellina kunlunensis、Ilyocypris bradyi 和 Limnocythere dubiosa 等几乎在各 类水体中均有分布, 其中 Leucocythere postericosta 和 Limnocytherellina kunlunensis 偏于真盐水和超盐水, 而 Ilyocypris bradyi 偏于淡水.

不同盐度水体内部介形类的分布情况差异较大 (图 2). 在淡水水体中介形类组合主要为 Eucypris rischtanica - Candona candida - Ilyocypris bradyi - Limnocythere dubiosa - Leucocythere dorsotuberosa - Leucocythere tropis; 在少盐水水体中介形类组合为 Eucypris rischtanica - Limnocytherellina kunlunensis - Ilyocypris bradyi-Limnocytherellina bispinosa - Limnocythere dubiosa - Limnocytherellina trispinosa - Leucocythere postericosta, 本次调查 的淡水和少盐水水体中,生物多样性以及各属种的丰富度均达到最大. Limnocytherellina 属的 3 个种均在少 盐水水体中发育繁盛. 本次调查的中盐水水体中, 仅分布有 Limnocythere dubiosa 1 个种, 且其壳瓣数也很少; 多盐水水体中介形类组合为 Limnocythere dubiosa-Eucypris inflata ; 真盐水水体中介形类组合为 Limnocythere 


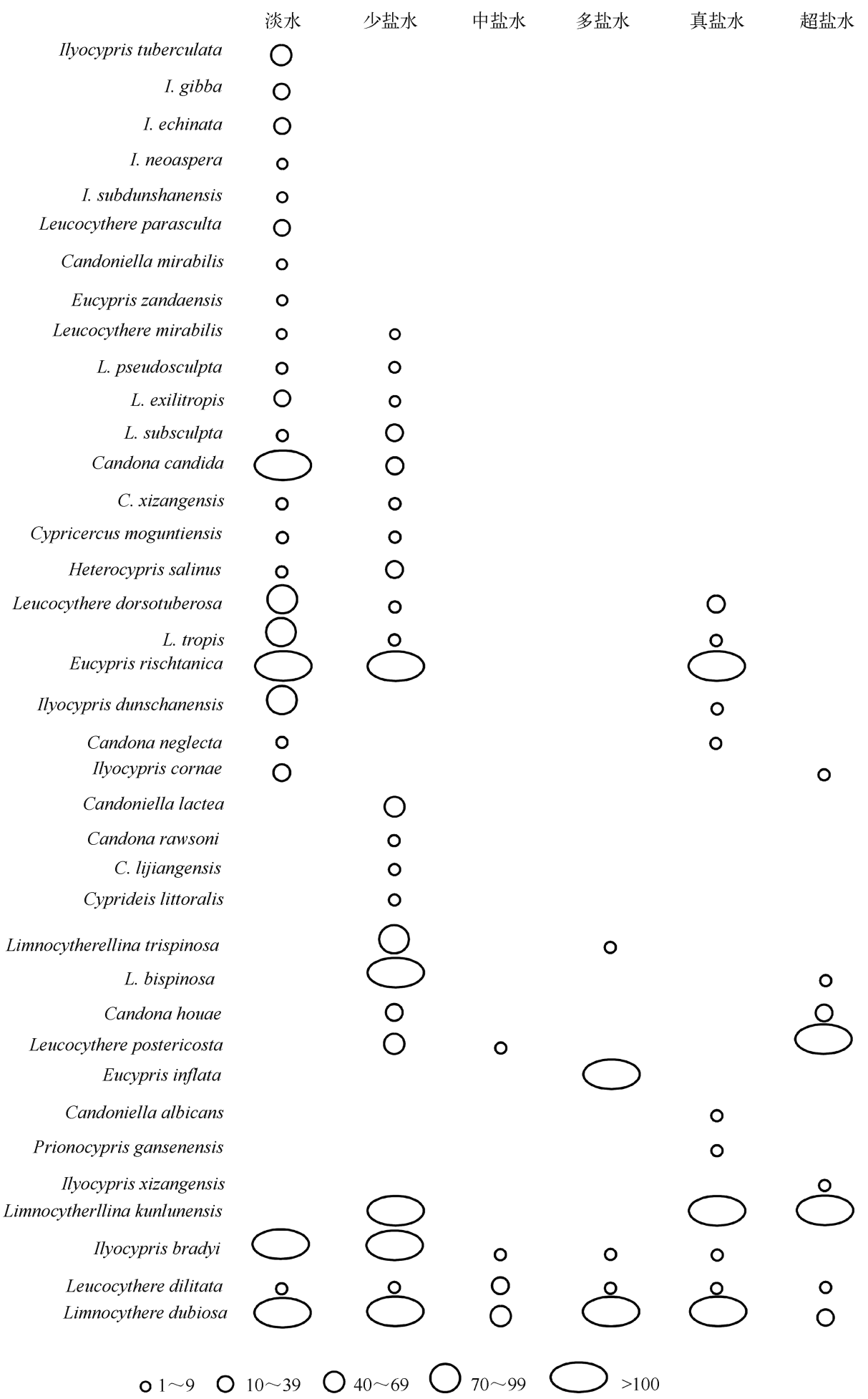

图 2 介形类各属种在不同盐度水体中的丰度分布

Fig. 2 The abundance of ostracodes in waters with different salinities 
dubiosa - Eucypris rischtanica - Limnocytherellina kunlunensis; 而在超盐水水体中介形类组合主要为 Limnocytherellina kunlunensis - Leucocythere postericosta.

\section{3 介形类分布的 $\mathrm{pH}$ 值范围}

水体的 $\mathrm{pH}$ 值也会对介形类的生长发育以及分布产生重要影响. 本文调查的水体 $\mathrm{pH}$ 值范围为 $6.30 \sim$ $11.43, \mathrm{pH}$ 值最低的格日错沉积物中没有发现介形虫壳体. 有介形类分布的水体 $\mathrm{pH}$ 值范围为 $6.80 \sim 11.14$. 介形虫壳体的主要成分是低镁的方解石, 因此其在酸性水体中不易保存, 格日错中没有发现介形虫, 可能有 这方面的原因. 但并非 $\mathrm{pH}$ 值越高介形虫壳体就越多, 错那对面湖泊 (样品号为 $\mathrm{xz}-22$ ) 的 $\mathrm{pH}$ 值为 11.43 , 在 该湖的沉积物中并没有发现介形虫的壳体.

Leucocythere 属分布较广泛, 在弱酸性、中性及碱性水体中均有分布, 其中总壳瓣数最多的种为 Leucocythere postericosta (145 枚), 该种均生活在 $\mathrm{pH}$ 值大于 8 的水体中; 出现频次最多的种为 Leucocythere dilitata (9 次), 该种只在 $\mathrm{pH}$ 值为 7.20 的错鄂出现 1 次, 其余皆出现在 $\mathrm{pH}$ 值大于 8 的水体中. Limnocythere dubiosa 出现频次最多 (27 次), 总壳瓣数也最多 (2127 枚), 也是唯一一个能生活在 $\mathrm{pH}$ 值大于 11 的强碱性水体中 的种. Limnocytherellina 属普遍能适应 $\mathrm{pH}$ 值较低的水体, 总壳瓣数最多的 Limnocytherellina kunlunensis (784 枚) 对其生活水体的 $\mathrm{pH}$ 值要求稍高一点, 为 7.20 , 而 Limnocytherellina bispinosa 和 Limnocytherellina trispinosa 均可在 $\mathrm{pH}$ 值为 6.80 的弱酸性水体中生存. Ilyocypris bradyi 是 Ilyocypris 属中出现频次最大 ( 20 次)、总壳瓣数 最多 (550 枚) 的种,也是该属中唯一一个既能适应弱酸性水体也能适应碱性水体的种, 而其它 Ilyocypris 种 只出现于弱碱性一碱性水体中,在弱酸性水体中未曾发现. Candona 属和 Candoniella 属中,除 Candona neglec$t a$ 在 $\mathrm{pH}$ 值为 7.20 的水体发现 1 枚外,其余所有属种均生活在 $\mathrm{pH}$ 值大于 8 的碱性水体中,这 2 个属是本次 研究中出现频率较高的属种中对水体 $\mathrm{pH}$ 值要求最严格的属. Eucypris rischtanica 是 Eucypris 属中出现频次最 大(9 次)、总壳瓣数最多 (1771 枚) 的种, 也是该属中唯一能适应弱酸性水体的种, Eucypris inflata 和 Eucypris zandaensis 出现频次少, 且只出现在碱性水体中 (表 1 ).

介形类属数在 $\mathrm{pH}$ 值为 $9 \sim 10$ 的水体中达到峰值, 而种数及总壳瓣数在 $\mathrm{pH}$ 值为 $8 \sim 9$ 的水体中最高 (图 3 ), 介形类繁殖发育达到鼎盛. 只有永珠藏布 ( YZ-1 点位) 和错鄂 ( CE-1 点位), $\mathrm{pH}$ 值分别为 6.80 和 7.20, 但二者的属种数却分别高达 4 属 7 种和 4 属 5 种, 其中永珠藏布介形类的丰度也较高, 达 270 枚 $/ 50 \mathrm{~g}$.
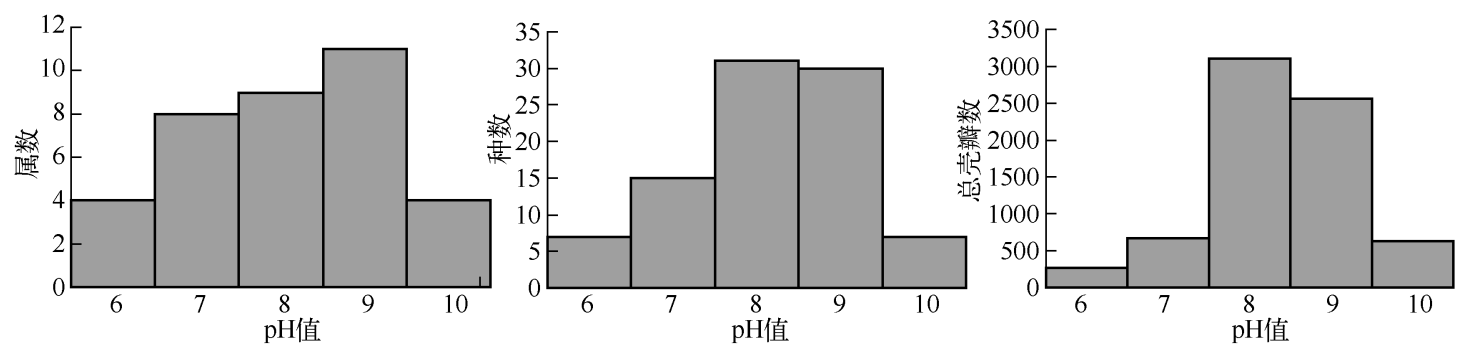

图 3 介形类属数、种数及总壳瓣数在不同 $\mathrm{pH}$ 值水体中的分布直方图

Fig. 3 Spread histograms of ostracods genus, species and abundance in water with different $\mathrm{pH}$ values

\section{3 讨论}

在影响内陆水体介形类分布的环境因素中, 首要控制因素是水体的盐度, 不同属种对其宿生水体盐度 升高的耐受程度各不相同 ${ }^{[16]}$. 本研究发现, 西藏阿里和那曲地区介形类广盐种以 Leucocythere dilitata、Limnocythere dubiosa、Limnocytherellina kunlunensis 和 Eucypris rischtanica 为主. Limnocythere dubiosa 不仅在各种盐度 的水体中都有发现,而且在各种栖息地中产出丰富, 表明 Limnocythere dubiosa 是西藏阿里和那曲地区分布最 广泛的种. 刘俊英等 ${ }^{[17]}$ 、王海雷等 ${ }^{[18-19]}$ 在对西藏地区介形类反映的环境进行研究时认为, Limnocythere dubio$s a$ 是适应性很强的种,在淡水、半咸水至咸水中均能生活, 为较喜盐的湖生咸水类型, 其在青海湖、苏干湖、 西藏的奇林湖、班戈湖、扎布耶湖、扎西错布、苛鲁湖、唐古拉山口等湖泊均有出现并且丰度较大, 另外在德 国相当于中更新统的 Holstein 冰湖沉积物中也曾见及,其多喜于湖底滩,尤其在碱性碳酸盐或碱性硫酸盐型 
湖泊中很繁盛. 杨留法等 ${ }^{[20]}$ 也认为在咸水湖泊沉积中该种特别丰富, 是适应性强的淡水一咸水种, 本文再次 印证了这一观点. Eucypris rischtanica 主要分布在湖泊中, 在流动性水体中亦可见. 该种曾发现于西藏吉隆属 淡水一微咸水的中更新世至全新世地层中, 张玲等 ${ }^{[5]}$ 在对青海湖地区不同水体介形类分布特征进行研究时 指出, 在水流较缓、水草丰富的浅水区介形类 Eucypris rischtanica 较丰富, 本研究发现 Eucypris rischtanica 不仅 适宜淡水一少盐水的环境, 而且在真盐水的环境中也能繁殖生长, 其样品主要采自真盐水的班戈湖, 在该湖 中 Eucypris rischtanica 是除 Limnocythere dubiosa 外的第二大优势种, 壳瓣数达 254 枚 $/ 50 \mathrm{~g}$, 表明 Eucypris rischtanica 在盐度较低的水体中常见, 但能耐受较高盐度, 具广盐性特征. Limnocytherellina kunlunensis 为庞其清 1985 年在昆仑山口发现的新种 ${ }^{[21]}$, 但仅记录了新种的形貌特征, 未讨论其环境指示意义. 本研究中, 该种在 少盐水、真盐水和超盐水中均大量出现, 能适应较广的盐度范围, 是偏盐水的广盐种. Leucocythere mirabilis 主 要产于淡水一少盐水的浅水环境, 但在该环境下该种的产量并不丰富, 庞其清等 ${ }^{[22]}$ 在西藏高原上的错那、扎 日南木错、班公错、雅各冬错和阿木错的现代湖泊底质中均发现此种, 表明此种为适应性强的广盐性种, 而 且适宜生活在较深水带, 本研究中 Leucocythere mirabilis 产量不丰富可能与采样点深度较浅有关; Leucocythere subsculpta 偏爱淡水一少盐水的动荡环境, 庞其清等 ${ }^{[22]}$ 在探讨西藏奇林湖与班戈湖介形类反映的气候环境时 也认为 Leucocythere subsculpta 的出现代表着湖水受流水作用影响, 且湖水矿化度低, 本文观点与其一致. 一 般认为 Ilyocypris bradyi 为广温性浅水种, 较喜暖, 为淡水河湖相种, 多生活于流动性水体. 本次研究中 Ilyocypris bradyi 为 Ilyocypris 属中分布最广泛、产量最高的种, 主要适宜淡水一少盐水的浅水环境, 在流动性水体 中也有一定产出. 刘俊英等 ${ }^{[23]}$ 在对古昆仑湖地区的介形类与环境变迁关系进行探讨时认为, Ilyocypris bradyi 属于适应性很强的喜于淡水、浅水的流动性水体栖息的无瘤型 Ilyocypris 分子, 在微咸水甚至湖面结冰的水 塘里也能找到, 其栖息水域的温度范围相当宽泛, 本文与其观点一致. Candona 属中分布最广、丰度最高的 Candona candida 主要分布于淡水湖泊、浅水坑环境中.一般认为 Candona candida 主要生活在永久性清澈、 富有机质的淡水水体底泥中, 是窄温性冷水种. 刘俊英等 ${ }^{[23]}$ 认为 Candona candida 为喜冷的淡水现生种, 可 生活在各种类型的水体和冰冻水坑中, 在昆仑湖 105 98 ka 的凉湿期介形类中, 其含量达 33\%, Carbonel 等 ${ }^{[24]}$ 和 Danielopol 等 ${ }^{[25]}$ 认为, Candona candida 主要生活在滨岸浅水带, 本文发现 Candona candida 主要出现 在水草丰富的浅水带黑色底泥中, 与前人研究结果一致. Candona neglect 出现在波罗的海, БроНШТейH 3 等 ${ }^{[26]}$ 认为其主要生活在淡水一半咸水的环境中. 本研究发现, Candona neglect 在淡水和真盐水环境中都有分 布, 进一步拓宽了其能适应的水体盐度范围. Candoniella albicans 被认为是淡水种 ${ }^{[26]}$, 本研究却在真盐水的 班戈湖中发现有 4 枚成年壳体, 壳体较干净, 未见石化等后期变质作用, 且采样点远离河口, 基本可以排除 其为河流带进地层中的化石, 表明此种亦能适应高盐度水体. 但因发现数量较少, 还需进一步的调查证实. 黄宝仁 ${ }^{[27]}$ 在对西藏现代湖泊表层沉积物中的介形类进行调查时发现, 在含盐度最高的马尔盖茶卡 $(323.46 \mathrm{~g} / \mathrm{L})$, 仅发现 Eucypris inflata一个种, 本文中 Eucypris inflata 亦在多盐的湖泊环境中大量出现, 再次 印证 Eucypris inflata 为典型的能耐高盐度的盐水种.

底质中的 $\mathrm{pH}$ 值与水体中动植物的生长具有一定关系 ${ }^{[28]}$. 本次调查的介形类主要分布在 $\mathrm{pH}$ 值为 $8 \sim 10$ 的偏碱性水体中. 赵宇蚔 ${ }^{[29]}$ 在探讨不同 $\mathrm{pH}$ 值水溶液对现生介形类壳体保存的影响时指出, 大多数淡水介 形类对其生活水体的 $\mathrm{pH}$ 值都有嗜碱性的生态特点, 除少数种可以适应略呈酸性的水体以外, 其余诸种能适 应的水体 $\mathrm{pH}$ 值一般均在 8 以上, 本次调查发现, 西藏阿里、那曲地区现生介形类对其生存水体的 $\mathrm{pH}$ 值要求 也符合这一特点, 但 Whatley 等 ${ }^{[30]}$ 在调查 Aberystwyth 河口和海湾介形类, 以及分析 Cyprideis lutea 和其它种 的标本数量时指出的介形类的个体数量峰值与 $\mathrm{pH}$ 值曲线的高峰相吻合这一特点在本地区不适用.

纵观表 1 可以发现, 介形类产量丰富的地点, 其水体 $\mathrm{pH}$ 值基本都在 8 以上. 从图 3 介形类各种生活水 体的 $\mathrm{pH}$ 值范围可以看出, 大部分介形类喜好偏碱性水体, 其生活的水体 $\mathrm{pH}$ 值基本都大于或等于 8 , Leucocythere dorsotuberosa、L. tropis、Limnocytherellina bispinosa、L. trispinosa、Ilyocypris bradyi 和 Eucypris rischtanica 6 个种可以适应 $\mathrm{pH}$ 值为 $6 \sim 7$ 的弱酸性水体, 而能适应 $\mathrm{pH}$ 值 $>10$ 的碱性水体的属种有 Leucocythere postericosta、L. mirabilis、L. subsculpta、Limnocythere dubiosa、Ilyocypris bradyi、Candona houae 和 C. candida. 适应性最广 的种是 Limnocythere dubiosa, 可适应 $\mathrm{pH}$ 值为 $7.20 \sim 11.14$ 的水体. Leucocythere 属和 Limnocytherellina 属对水 体 $\mathrm{pH}$ 值的适应范围较广, Candona 属和 Candoniella 属生活的水体 $\mathrm{pH}$ 值都在 8 以上, 只有 Candona neglecta 
生活的水体 $\mathrm{pH}$ 值最低, 为 7.20 , 这一结果与前人研究成果一致 ${ }^{[31]} .1969$ 年 Delorme ${ }^{[32]}$ 指出, Candona rawsoni 对 $\mathrm{pH}$ 值的适应范围较广, 在 $7.20 \sim 12.00$ 之间, 本次研究仅在一个地点发现 Candona rawsoni, 但其 $\mathrm{pH}$ 值为 9.16,仍在该范围之内. Limnocythere dubiosa 和 Eucypris inflata 在青藏高原多地均有发现,但大多没有提及采 集时的 $\mathrm{pH}$ 值, 仅黄宝仁等 ${ }^{[33]}$ 在对青海湖第四纪介形类进行研究时指出, 在 $\mathrm{pH}$ 值为 9.10 9.40 的水体中, 存在的现生介形类仅为 Limnocythere dubiosa 和 Eucypris inflata. 本次研究发现 Eucypris inflata 的 $\mathrm{pH}$ 值适应范 围为 $9.40 \sim 9.70$, 基本与之前的调查范围一致. 但 Limnocythere dubiosa 的 $\mathrm{pH}$ 值适应范围为 $7.20 \sim 11.14$,大 大高于之前该种的 $\mathrm{pH}$ 值适应范围, 表明该种是能适应很广的 $\mathrm{pH}$ 值范围的现生介形类.

\section{4 结论}

1) 西藏阿里和那曲地区常见的现生介形类属种有 Ilyocypris bradyi、Limnocythere dubiosa、Eucypris rischtanica、Limnocytherellina kunlunensis、Candona candida 和Leucocythere dilitata, 其中 Limnocythere dubiosa 在 61 个 采样水体中的 27 个中出现, 为该地区分布最广的现生介形类, Ilyocypris bradyi 以 20 个次之.

2 ) Leucocythere dilitata、Limnocythere dubiosa、Limnocytherellina kunlunensis 和 Eucypris rischtanica 为西藏阿 里和那曲地区的广盐种. 其中 Limnocythere dubiosa 和 Leucocythere dilitata 适应盐度范围最广, 在不同盐度的 各类水体中都能发育. Limnocytherellina kunlunensis 为偏盐水的广盐种. Eucypris rischtanica 在盐度较低的水体 中常见,但能耐受较高盐度.

3 ) 本次调查发现有介形类分布的水体 $\mathrm{pH}$ 值范围为 $6.80 \sim 11.14$, 介形类集中分布在 $\mathrm{pH}$ 值为 $8 \sim 10$ 的 偏碱性水体中. Limnocythere dubiosa 对水体 $\mathrm{pH}$ 值的适应范围拓宽至 $7.20 \sim 11.14$, 大大高于之前记录的 $9.10 \sim 9.40$. Leucocythere dorsotuberosa、L. tropis、Limnocytherellina bispinosa、L. trispinosa、Ilyocypris bradyi 和 Eucypris rischtanica 等 6 个种能适应弱酸性水体, 而Leucocythere postericosta、L. mirabilis、L. subsculpta、Limnocythere dubiosa、Ilyocypris bradyi、Candona houae 和 C. candida 7 个种能适应 $\mathrm{pH}$ 值 $>10$ 的碱性水体.

致谢: 感谢杨藩教授在介形类属种鉴定过程中给予的指导帮助. 感谢刘俊英研究员对本文有益的探讨和建 议. 感谢兰州大学张成君教授, 张范渏、㚞荣博士研究生, 赵琦、胡军硕士研究生协助野外工作.

\section{5 参考文献}

[ 1 ] Zheng MP. An introduction to saline lakes on the Qinghai-Tibet Plateau. Dordrecht: Springer Netherlands, 1997: 4554,168 .

[ 2 ] Whatley R. Population structure of ostracods: some general principles for recognition of palaeoenvironments. In: de Deckker P, Colin JP, Peypouquet JP eds. Ostracoda in the earth sciences. Amsterdam: Elsevier, 1988: 245-256.

[ 3 ] Mezquita F, Roca JR, Reed JM et al. Quantifying species - environment relationships in non-marine ostracoda for ecological and palaeoecological studies: examples using Iberian data. Palaeogeography, Palaeoclimatology, Palaeoecology, 2005,225 : 93-117.

[ 4 ] 禹 娜, 陈立侨, 赵泉鸿. 太湖介形虫分布与水环境因子间关系的典范对应分析. 微体古生物学报, 2007,24 (1): $53-60$.

[5] 张 玲, 孙镇城, 安芷生等. 青海湖区不同水体介形类分布特征的初步研究. 微体古生物学报, 2006, 23 (4): 425-436.

[6]卢风艳, 安芷生. 青海湖表层沉积物介形虫丰度及其壳体氧同位素的气候环境意义. 海洋地质与第四纪地质, $2010,30(5): 119-128$.

[ 7 ] 孔 嫱,禹 娜, 赵泉鸿. 贵州省红枫湖现生介形类新纪录. 微体古生物学报,2013,30(2):166-174.

[ 8 ] 禹 娜,赵泉鸿, 成金荃. 云南滇池淡水介形类新纪录. 微体古生物学报, 2010,27(4):344-350.

[ 9 ] 杨留法.黄宝仁. 云南抚仙湖表层沉积物中的介形类及其分布规律的初步研究. 科学通报, 1983,10:617-621.

[10］杨 藩, 乔子真, 张海泉等. 柴达木盆地新生代介形类动物群特征及环境意义. 古地理学报, 2006,8(2):143-156.

[11］黄宝仁, 杨留法, 范云琦. 西藏现代湖泊表层沉积物中的介形类. 微体古生物学报, 1985,2 (4):376-396.

[12] Mischke S, Herzschuh U, Massmann G et al. An ostracod-conductivity transfer function for Tibetan lakes. Journal of Paleolimnology, 2007, 38(4) : 509-524.

[13 ] Mischke S, Bößneck U, Diekmann B et al. Quantitative relationship between water-depth and sub-fossil ostracod assem- 
blages in Lake Donggi Cona, Qinghai Province, China. Journal of Paleolimnology, 2010, 43(3) : 589-608.

[14] 侯佑堂,勾韵䢞,陈德琼. 中国介形类化石:第一卷. 北京:科学出版社,2002.

[15] 侯佑堂,勾韵娴,陈德琼. 中国介形类化石:第二卷. 北京:科学出版社,2007.

[16] 杨 藩. 柴达木盆地第四纪介形类与环境变迁. 见: 中国古生物学会编. 中国古生物学会十三、十四届学术年会议 论文选集. 合肥: 安徽科学技术出版社,1986:297-284.

[17] 刘俊英, 王海雷, 袁鹤然. 西藏色卡执湖区更新世晚期以来微体古生物记录的气候演变. 地质学报, 2010,84 (11): 1668-1679.

[18］王海雷,刘俊英, 王成敏. 青藏高原日土地区全新世中期以来介形类和孢粉组合变化及其古环境意义. 地质学报, 2010,84 (11): 1680-1689.

[19］王海雷,王云生. 青藏高原湖泊 $\mathrm{Mg}^{2+} 、 \mathrm{Ca}^{2+}$ 和 $\mathrm{Mg} / \mathrm{Ca}$ 盐度指示意义的初步研究. 湖泊科学, 2010,22 (6) :894-900. DOI 10. 18307/2010.0612.

[20］杨留法, 范云崎, 黄宝仁. 西藏高原现代湖泊沉积物中的介形类化石及其与湖水矿化度间关系的初步研究. 海洋湖 沼通报,1982,(1) :20-28.

[21］庞其清. 青藏高原昆仑山口更新世介形类的一新属. 青藏高原地质文集,1985,(16):269-276.

[22] 庞其清, 郑绵平, 刘文高. 西藏奇林湖一班戈湖地区晚新生代介形虫化石及其地层意义. 见: 中国地质学会编. 青藏 高原地质文集. 北京: 地质出版社, 1985:243-264.

[23] 刘俊英, 郑绵平, 王海雷. 古昆仑湖地区 183-90kaBP 间的微体古生物与环境变迁. 湖泊科学, 2010,22(5):739748. DOI 10. 18307/2010.0517.

[24] Carbonel P, Colin JP, Danielopol DL et al. Palaeoecology of limnic ostracodes: a review of same major topics. Palaeogeography, Palaeoclimatology, Palaeoecology, 1988, 62: 413-461.

[25] Danielopol DL, Handl M, Yu Y. Benthic ostracods in the prealpine deep lake Mondsee, nates on their origin and distribution. In: Mcknzie KG, Jones PJ eds. Ostracoda in the earth and life science. Rotterdam: Balkema, 1993 : 465-479.

[26] БроНШТейН 3, С. ФауНа СССР. РакообразНИе, ТОМ. II , ВИІІ. 1, Ostracoda пресНИх НОВ. сер. ВОп. Зооп. ИН-Та АН СССР, ВИІІ. 1947 : 31.

[27] 黄宝仁. 桑干河中下游流域更新世介形类及其地质意义. 南京: 中国科学院南京地质古生物研究所集刊, 1985: 85-107.

[28] 范成新, 季 江, 隋桂荣. 太湖底泥蓄积和主要理化性质空间分布特征. 见: 蔡启铭编. 太湖环境生态研究. 北京:气 象出版社,1998:55-61.

[29］赵宇虹. 不同 $\mathrm{pH}$ 值水溶液对现生介形类壳体保存的影响. 微体古生物学报,1990,7(1):1-8.

[30 ] Whatley RC, Wall DR. A preliminary account of the ecology and distribution of recent ostracoda in the Southern Irish Sea. In: Neale JW ed. The taxonomy, morphology and ecology of recent Ostracoda. Edinburgh: Oliver \& boyd, 1988: 268-298

[31] Klassen RW, Delorme LD. Geology and paleontology of Pleistocene deposits in southwestern Manitoba. Canadian Journal of Earth Sciences, 1967, 4(3): 433-447.

[32 ] Delorme LD. Ostracods as Quaternary paleoecological indicators. Canadian Journal of Earth Sciences, 1969, 6(6) : 14711476.

[33] 黄宝仁, 郭书元. 青海湖区第四纪介形类 - 中国科学院南京地质古生物研究所丛刊, 第 7 号. 南京: 江苏科技出版 社, 1984:187-236. 
附表 西藏地区各水体自然要素及表层沉积物中介形类属、种、丰度分布

Attached Table Environment factors and distribution of ostracods genus, species and abundance in the surface sediment in Tibet

\begin{tabular}{|c|c|c|c|c|c|c|c|c|c|c|}
\hline \multirow[b]{2}{*}{ 序号 } & \multirow[b]{2}{*}{ 样号 } & \multirow[b]{2}{*}{ 采样点 } & \multirow[b]{2}{*}{ 位置 } & \multirow[b]{2}{*}{$\begin{array}{c}\text { 海拔/ } \\
\text { m }\end{array}$} & \multirow[b]{2}{*}{$\begin{array}{l}\text { 盐度/ } \\
\% 0\end{array}$} & \multirow[b]{2}{*}{$\mathrm{pH}$ 值 } & \multirow[b]{2}{*}{$\begin{array}{l}\text { 采样点 } \\
\text { 水深 } / \mathrm{m}\end{array}$} & \multirow[b]{2}{*}{ 水体底质 } & \multicolumn{2}{|c|}{ 介形虫壳体 } \\
\hline & & & & & & & & & $\begin{array}{l}\text { 属/ } \\
\text { 种数 }\end{array}$ & $\begin{array}{l}\text { 总売瓣数/ } \\
\text { (枚 } / 50 \mathrm{~g})\end{array}$ \\
\hline 1 & CE-1 & 错鄂 & $\begin{array}{l}31^{\circ} 41^{\prime} 22^{\prime \prime} \mathrm{N} \\
89^{\circ} 26^{\prime} 22^{\prime \prime} \mathrm{E}\end{array}$ & 4546 & 0.27 & 7.20 & 0.5 & 含砾中细砂 & $4 / 5$ & 19 \\
\hline 2 & CE-2 & & $\begin{array}{l}31^{\circ} 38^{\prime} 08^{\prime \prime} \mathrm{N} \\
88^{\circ} 50^{\prime} 18^{\prime \prime} \mathrm{E}\end{array}$ & & & 7.40 & 0.4 & 巨砾中粗砂 & - & - \\
\hline 3 & GR-1 & 格日错 & $\begin{array}{l}31^{\circ} 12^{\prime} 28^{\prime \prime} \mathrm{N} \\
88^{\circ} 44^{\prime} 42^{\prime \prime} \mathrm{E}\end{array}$ & 4655 & 0.18 & 6.30 & 0.4 & 含细砂泥 & - & - \\
\hline 4 & BC-1 & 崩错 & - & 4733 & 0.29 & 8.20 & 0.6 & 含水草湖泥 & $4 / 15$ & 76 \\
\hline 5 & JCD-1 & 江错湖 & - & 4611 & 0.47 & 7.90 & 0.5 & 含黏土粉细砂 & $3 / 8$ & 410 \\
\hline 6 & JCD-2 & 边浅坑 & - & & & 7.30 & 0.2 & 含粉细砂黏土 & $2 / 2$ & 2 \\
\hline 7 & $X Q-1$ & 夏穷错 & - & 4641 & 0.47 & 8.30 & 0.5 & $\begin{array}{l}\text { 含砾水草中细砂, 黑色 } \\
\text { 有机质丰富 }\end{array}$ & $3 / 5$ & 14 \\
\hline 8 & $\mathrm{XQ}-2$ & & - & & & 8.40 & 0.5 & 含砾水草中细砂 & $2 / 3$ & 80 \\
\hline 9 & $X Q-3$ & & - & & & 8.60 & 0.5 & 含砾水草中细砂 & $3 / 5$ & 739 \\
\hline 10 & $\mathrm{YC}-1$ & $\begin{array}{l}\text { 羊卓 } \\
\text { 雍错 }\end{array}$ & $\begin{array}{l}29^{\circ} 11^{\prime} 04^{\prime \prime} \mathrm{N}, \\
90^{\circ} 36^{\prime} 14^{\prime \prime} \mathrm{E}\end{array}$ & 4425 & 1.64 & 9.20 & 0.5 & 含水草细砂黏土 & $5 / 7$ & 80 \\
\hline 11 & YC-2 & & $\begin{array}{l}29^{\circ} 10^{\prime} 26^{\prime \prime} \mathrm{N} \\
90^{\circ} 37^{\prime} 10^{\prime \prime} \mathrm{E}\end{array}$ & & & 8.20 & 0.6 & 含黏土粉细砂 & $3 / 5$ & 47 \\
\hline 12 & $\mathrm{YC}-3$ & & $\begin{array}{l}29^{\circ} 10^{\prime} 26^{\prime \prime} \mathrm{N}, \\
90^{\circ} 37^{\prime} 10^{\prime \prime} \mathrm{E}\end{array}$ & & & 8.20 & 0.5 & $\begin{array}{l}\text { 黑色含水草粉细砂, 有 } \\
\text { 机质丰富 }\end{array}$ & $6 / 10$ & 419 \\
\hline 13 & YZ-1 & $\begin{array}{l}\text { 永珠 } \\
\text { 藏布 }\end{array}$ & $\begin{array}{l}31^{\circ} 12^{\prime} 28^{\prime \prime} \mathrm{N} \\
88^{\circ} 44^{\prime} 42^{\prime \prime} \mathrm{E}\end{array}$ & 4655 & 1.65 & 6.80 & 0.3 & $\begin{array}{l}\text { 略含砾黏土, 有机质 } \\
\text { 丰富 }\end{array}$ & $4 / 7$ & 270 \\
\hline 14 & YZ-2 & & - & & & 6.50 & 0.2 & 含黏土砂砾 & - & - \\
\hline 15 & PC-1 & 蓬错 & - & 4523 & 11.48 & 10.00 & 0.6 & 含砾含泥中粗砂 & - & - \\
\hline 16 & PC-2 & & - & & & 10.00 & 0.6 & 含砾含泥中粗砂 & - & - \\
\hline 17 & JC-1 & 江错 & $\begin{array}{l}31^{\circ} 31^{\prime} 42^{\prime \prime} \mathrm{N} \\
90^{\circ} 51^{\prime} 05^{\prime \prime} \mathrm{E}\end{array}$ & 4611 & 28.6 & 9.40 & 10 & $\begin{array}{l}\text { 含水草种子皮壳粉细 } \\
\text { 砂黏土 }\end{array}$ & $2 / 2$ & 285 \\
\hline 18 & JC-2 & & $\begin{array}{l}31^{\circ} 31^{\prime} 41^{\prime \prime} \mathrm{N} \\
90^{\circ} 51^{\prime} 07^{\prime \prime} \mathrm{E}\end{array}$ & & & 9.60 & 10 & 粉细砂黏土, 水草较多 & $2 / 2$ & 277 \\
\hline 19 & JC-3 & & $\begin{array}{l}31^{\circ} 31^{\prime} 41^{\prime \prime} \mathrm{N} \\
90^{\circ} 52^{\prime} 11^{\prime \prime} \mathrm{E}\end{array}$ & & & 9.60 & 9 & 粉细砂黏土, 水草较多 & $2 / 2$ & 516 \\
\hline
\end{tabular}




\begin{tabular}{|c|c|c|c|c|c|c|c|c|c|c|}
\hline \multirow[b]{2}{*}{ 序号 } & \multirow[b]{2}{*}{ 样号 } & \multirow[b]{2}{*}{ 采样点 } & \multirow[b]{2}{*}{ 位置 } & \multirow{2}{*}{$\begin{array}{c}\text { 海拔/ } \\
\mathrm{m}\end{array}$} & \multirow{2}{*}{$\begin{array}{c}\text { 盐度/ } \\
\% o\end{array}$} & \multirow[b]{2}{*}{$\mathrm{pH}$ 值 } & \multirow{2}{*}{$\begin{array}{l}\text { 采样点 } \\
\text { 水深 } / \mathrm{m}\end{array}$} & \multirow[b]{2}{*}{ 水体底质 } & \multicolumn{2}{|c|}{ 介形虫壳体 } \\
\hline & & & & & & & & & $\begin{array}{l}\text { 属/ } \\
\text { 种数 }\end{array}$ & $\begin{array}{l}\text { 总壳瓣数/ } \\
(\text { 枚/50 g })\end{array}$ \\
\hline 20 & BG-1 & 班戈湖 & $\begin{array}{l}31^{\circ} 41^{\prime} 48^{\prime \prime} \mathrm{N}, \\
89^{\circ} 26^{\prime} 39^{\prime \prime} \mathrm{E}\end{array}$ & 4523 & 37.46 & 9.70 & 1.5 & $\begin{array}{l}\text { 含粉细砂黏土, 有机质 } \\
\text { 多, 较多水草种子皮壳 }\end{array}$ & $2 / 2$ & 3 \\
\hline 21 & BG-2 & & $\begin{array}{l}31^{\circ} 41^{\prime} 53^{\prime \prime} \mathrm{N} \\
89^{\circ} 26^{\prime} 44^{\prime \prime} \mathrm{E}\end{array}$ & & & 9.80 & 1.7 & $\begin{array}{l}\text { 含粉细砂黏土, 黑色有 } \\
\text { 机质多 }\end{array}$ & $1 / 1$ & 76 \\
\hline 22 & BG-3 & & $\begin{array}{l}31^{\circ} 41^{\prime} 52^{\prime \prime} \mathrm{N} \\
89^{\circ} 26^{\prime} 48^{\prime \prime} \mathrm{E}\end{array}$ & & & 9.90 & 1.8 & $\begin{array}{l}\text { 含粉细砂黏土, 有机质 } \\
\text { 多,大量水草种子皮壳 }\end{array}$ & $4 / 7$ & 350 \\
\hline 23 & BG-4 & & $\begin{array}{l}31^{\circ} 41^{\prime} 49^{\prime \prime} \mathrm{N}, \\
89^{\circ} 26^{\prime} 47^{\prime \prime} \mathrm{E}\end{array}$ & & & 10.00 & 1.5 & $\begin{array}{l}\text { 含粉细砂黏土, 有机质 } \\
\text { 多,水草种子皮壳丰富 }\end{array}$ & $1 / 1$ & 735 \\
\hline 24 & BG-5 & & $\begin{array}{l}31^{\circ} 41^{\prime} 49^{\prime \prime} \mathrm{N}, \\
89^{\circ} 26^{\prime} 47^{\prime \prime} \mathrm{E}\end{array}$ & & & 9.70 & 0.5 & 含黏土粉细砂 & $1 / 1$ & 85 \\
\hline 25 & BG-2-1 & & - & & & 9.70 & 0.6 & 含水草湖泥 & $6 / 10$ & 42 \\
\hline 26 & BG-2-2 & & - & & & 9.60 & 0.4 & 含水草湖泥 & $1 / 1$ & 111 \\
\hline 27 & BG-6 & $\begin{array}{l}\text { 班戈湖 } \\
\text { 边浅坑 }\end{array}$ & $\begin{array}{l}31^{\circ} 41^{\prime} 48^{\prime \prime} \mathrm{N} \\
89^{\circ} 28^{\prime} 22^{\prime \prime} \mathrm{E}\end{array}$ & 4543 & 0.65 & 7.30 & 0.5 & 含砾中细砂 & $1 / 1$ & 2 \\
\hline 28 & DX-1 & 当雄错 & - & - & 163 & - & - & 细砂黏土, 水草丰富 & $1 / 1$ & 105 \\
\hline 29 & DX-2 & & - & & & - & - & $\begin{array}{l}\text { 粗中砂黏土, 含少量 } \\
\text { 砾石 }\end{array}$ & $4 / 4$ & 53 \\
\hline 30 & $\mathrm{xz}-1$ & 错鄂 & $\begin{array}{l}31^{\circ} 34^{\prime} 16^{\prime \prime} \mathrm{N}, \\
91^{\circ} 31^{\prime} 31^{\prime \prime} \mathrm{E}\end{array}$ & 4541 & 0.68 & 9.16 & 0.2 & 底质泥 & $4 / 4$ & 54 \\
\hline 31 & $\mathrm{xz}-2$ & 懂错 & $\begin{array}{l}31^{\circ} 35^{\prime} 36^{\prime \prime} \mathrm{N} \\
91^{\circ} 07^{\prime} 29^{\prime \prime} \mathrm{E}\end{array}$ & 4580 & 1.46 & 9.16 & 0.2 & 底质泥, 含浮游生物 & - & - \\
\hline 32 & $x z-3$ & 蓬错 & $\begin{array}{l}31^{\circ} 23^{\prime} 37^{\prime \prime} \mathrm{N}, \\
90^{\circ} 56^{\prime} 39^{\prime \prime} \mathrm{E}\end{array}$ & 4557 & 12.06 & 10.08 & 5.0 & 底质泥, 含浮游生物 & $1 / 1$ & 34 \\
\hline 33 & $x z-4$ & $\begin{array}{l}\text { 那曲西 } \\
\text { 浅水坑 }\end{array}$ & $\begin{array}{l}31^{\circ} 23^{\prime} 56^{\prime \prime} \mathrm{N} \\
90^{\circ} 53^{\prime} 45^{\prime \prime} \mathrm{E}\end{array}$ & 4595 & 0.35 & 8.56 & 0.5 & 底质泥 & - & - \\
\hline 34 & $\mathrm{xz}-5$ & $\begin{array}{l}\text { 班戈西 } \\
\text { 小湖泊 }\end{array}$ & $\begin{array}{l}31^{\circ} 29^{\prime} 50^{\prime \prime} \mathrm{N} \\
89^{\circ} 55^{\prime} 38^{\prime \prime} \mathrm{E}\end{array}$ & 4701 & 1.14 & 10.56 & 0.2 & 含水草湖泥 & $1 / 1$ & 5 \\
\hline 35 & $x z-6$ & & $\begin{array}{l}31^{\circ} 29^{\prime} 30^{\prime \prime} \mathrm{N} \\
89^{\circ} 55^{\prime} 12^{\prime \prime} \mathrm{E}\end{array}$ & 4694 & 0.42 & 11.14 & 2.0 & 湖泥,水草丰富 & $1 / 1$ & 1 \\
\hline 36 & $\mathrm{xz}-7$ & $\begin{array}{l}\text { 班戈西 } \\
\text { 浅水坑 }\end{array}$ & $\begin{array}{l}31^{\circ} 28^{\prime} 42^{\prime \prime} \mathrm{N}, \\
89^{\circ} 55^{\prime} 3^{\prime \prime} \mathrm{E}\end{array}$ & 4747 & 0.25 & 8.68 & 0.3 & $\begin{array}{l}\text { 底 泥, 含 水 草、浮 游 } \\
\text { 生物 }\end{array}$ & $2 / 2$ & 2 \\
\hline 37 & $\mathrm{xz}-8$ & $\begin{array}{l}\text { 班戈西 } \\
\text { 小湖泊 }\end{array}$ & $\begin{array}{l}31^{\circ} 28^{\prime} 18^{\prime \prime} \mathrm{N} \\
89^{\circ} 54^{\prime} 7^{\prime \prime} \mathrm{E}\end{array}$ & 4747 & 0.29 & 9.01 & 0.2 & 湖泥 & $4 / 4$ & 63 \\
\hline 38 & $x z-9$ & & $\begin{array}{l}31^{\circ} 28^{\prime} 32^{\prime \prime} \mathrm{N}, \\
89^{\circ} 53^{\prime} 5^{\prime \prime} \mathrm{E}\end{array}$ & 4727 & 0.28 & 9.01 & 0.2 & 粉砂质泥 & $6 / 6$ & 49 \\
\hline
\end{tabular}




\begin{tabular}{|c|c|c|c|c|c|c|c|c|c|c|}
\hline \multirow[b]{2}{*}{ 序号 } & \multirow[b]{2}{*}{ 样号 } & \multirow[b]{2}{*}{ 采样点 } & \multirow[b]{2}{*}{ 位置 } & \multirow[b]{2}{*}{$\begin{array}{c}\text { 海拔/ } \\
\mathrm{m}\end{array}$} & \multirow{2}{*}{$\begin{array}{c}\text { 盐度/ } \\
\% 0\end{array}$} & \multirow[b]{2}{*}{$\mathrm{pH}$ 值 } & \multirow{2}{*}{$\begin{array}{l}\text { 采样点 } \\
\text { 水深/m }\end{array}$} & \multirow[b]{2}{*}{ 水体底质 } & \multicolumn{2}{|c|}{ 介形虫壳体 } \\
\hline & & & & & & & & & $\begin{array}{l}\text { 属/ } \\
\text { 种数 }\end{array}$ & $\begin{array}{l}\text { 总壳瓣数/ } \\
(\text { 枚/50 g) }\end{array}$ \\
\hline 39 & $x z-10$ & $\begin{array}{l}\text { 班戈西 } \\
\text { 小湖泊 }\end{array}$ & $\begin{array}{l}31^{\circ} 28^{\prime} 26^{\prime \prime} \mathrm{N}, \\
89^{\circ} 53^{\prime} 8^{\prime \prime} \mathrm{E}\end{array}$ & 4782 & 0.34 & 8.76 & 0.3 & 含砾粉砂质泥 & $5 / 5$ & 469 \\
\hline 40 & $\mathrm{xz}-11$ & & $\begin{array}{l}31^{\circ} 28^{\prime} 10^{\prime \prime} \mathrm{N} \\
89^{\circ} 53^{\prime} 50^{\prime \prime} \mathrm{E}\end{array}$ & 4752 & 0.27 & 9.62 & 0.2 & 湖泥 & $4 / 4$ & 93 \\
\hline 41 & $x z-12$ & & $\begin{array}{l}31^{\circ} 28^{\prime} 56^{\prime \prime} \mathrm{N}, \\
89^{\circ} 52^{\prime} 12^{\prime \prime} \mathrm{E}\end{array}$ & 4791 & 0.53 & 10.95 & 0.5 & 泥质粉砂 & $1 / 1$ & 6 \\
\hline 42 & $\mathrm{xz}-13$ & $\begin{array}{l}\text { 班戈西 } \\
\text { 浅水坑 }\end{array}$ & $\begin{array}{l}31^{\circ} 28^{\prime} 16^{\prime \prime} \mathrm{N}, \\
89^{\circ} 48^{\prime} 46^{\prime \prime} \mathrm{E}\end{array}$ & 4596 & 0.40 & 8.95 & 0.3 & 底泥 & $4 / 5$ & 290 \\
\hline 43 & $x z-14$ & $\begin{array}{l}\text { 班戈湖 } \\
\text { 西小湖 }\end{array}$ & $\begin{array}{l}31^{\circ} 36^{\prime} 26^{\prime \prime} \mathrm{N}, \\
89^{\circ} 37^{\prime} 38^{\prime \prime} \mathrm{E}\end{array}$ & 4611 & 2.80 & 9.65 & 0.1 & 底泥 & - & - \\
\hline 44 & $\mathrm{xz}-15$ & $\begin{array}{l}\text { 路边 } \\
\text { 浅水坑 }\end{array}$ & $\begin{array}{l}31^{\circ} 36^{\prime} 34^{\prime \prime} \mathrm{N}, \\
89^{\circ} 37^{\prime} 33^{\prime \prime} \mathrm{E}\end{array}$ & 4608 & 2.60 & 9.68 & 0.2 & 底泥 & - & - \\
\hline 45 & $x z-16$ & $\begin{array}{l}\text { 班戈 } \\
\text { 西小湖 }\end{array}$ & $\begin{array}{l}31^{\circ} 36^{\prime} 41^{\prime \prime} \mathrm{N}, \\
89^{\circ} 37^{\prime} 7^{\prime \prime} \mathrm{E}\end{array}$ & 4660 & 1.12 & 10.69 & 0.2 & 水草丰富的湖泥 & $2 / 2$ & 5 \\
\hline 46 & $\mathrm{xz}-17$ & & $\begin{array}{l}31^{\circ} 36^{\prime} 41^{\prime \prime} \mathrm{N}, \\
89^{\circ} 36^{\prime} 46^{\prime \prime} \mathrm{E}\end{array}$ & 4657 & 0.38 & 10.26 & 0.2 & 粉砂质泥, 水草丰富 & - & - \\
\hline 47 & $\mathrm{xz}-18$ & & $\begin{array}{l}31^{\circ} 36^{\prime} 57^{\prime \prime} \mathrm{N}, \\
89^{\circ} 35^{\prime} 56^{\prime \prime} \mathrm{E}\end{array}$ & 4608 & 0.65 & 9.97 & 0.2 & 底泥, 含水草 & - & - \\
\hline 48 & $x z-19$ & $\begin{array}{l}\text { 班戈 } \\
\text { 西湖泊 }\end{array}$ & $\begin{array}{l}31^{\circ} 29^{\prime} 47^{\prime \prime} \mathrm{N} \\
88^{\circ} 56^{\prime} 28^{\prime \prime} \mathrm{E}\end{array}$ & 4576 & 5.12 & 10.34 & 0.2 & 含粉砂湖泥, 有水草 & - & - \\
\hline 49 & $\mathrm{xz}-20$ & & $\begin{array}{l}31^{\circ} 32^{\prime} 39^{\prime \prime} \mathrm{N} \\
88^{\circ} 52^{\prime} 18^{\prime \prime} \mathrm{E}\end{array}$ & 4589 & 0.22 & 9.53 & 0.3 & 粉砂质湖泥 & $2 / 2$ & 6 \\
\hline 50 & $\mathrm{xz}-21$ & 错那 & $\begin{array}{l}31^{\circ} 39^{\prime} 8^{\prime \prime} \mathrm{N} \\
88^{\circ} 51^{\prime} 7^{\prime \prime} \mathrm{E}\end{array}$ & 4580 & 0.37 & 9.03 & 0.5 & 底泥 & - & - \\
\hline 51 & $\mathrm{xz}-22$ & $\begin{array}{l}\text { 错那对 } \\
\text { 面小湖 }\end{array}$ & $\begin{array}{l}31^{\circ} 39^{\prime} 54^{\prime \prime} \mathrm{N}, \\
88^{\circ} 49^{\prime} 25^{\prime \prime} \mathrm{E}\end{array}$ & 4582 & 6.50 & 11.43 & 0.2 & 泥质粉砂 & - & - \\
\hline 52 & $x z-23$ & $\begin{array}{l}\text { 班戈 } \\
\text { 西湖泊 }\end{array}$ & $\begin{array}{l}31^{\circ} 47^{\prime} 8^{\prime \prime} \mathrm{N} \\
88^{\circ} 27^{\prime} 6^{\prime \prime} \mathrm{E}\end{array}$ & 4562 & 0.38 & 8.79 & 0.3 & 含粉砂泥 & - & - \\
\hline 53 & $x z-24$ & & $\begin{array}{l}31^{\circ} 47^{\prime} 36^{\prime \prime} \mathrm{N}, \\
88^{\circ} 27^{\prime} 4^{\prime \prime} \mathrm{E}\end{array}$ & 4569 & 3.32 & 9.25 & 0.2 & 底泥, 含水草 & - & - \\
\hline 54 & $\mathrm{xz}-25$ & $\begin{array}{l}\text { 班戈 } \\
\text { 西小湖 }\end{array}$ & $\begin{array}{l}31^{\circ} 50^{\prime} 22^{\prime \prime} \mathrm{N} \\
88^{\circ} 04^{\prime} 34^{\prime \prime} \mathrm{E}\end{array}$ & 4782 & 0.29 & 8.48 & 0.3 & 湖泥 & - & - \\
\hline 55 & $x z-26$ & 洞错 & $\begin{array}{l}32^{\circ} 50^{\prime} 33^{\prime \prime} \mathrm{N} \\
84^{\circ} 40^{\prime} 43^{\prime \prime} \mathrm{E}\end{array}$ & 4410 & 52.41 & 9.07 & - & 湖泥 & - & - \\
\hline 56 & $x z-27$ & 麻米错 & $\begin{array}{l}32^{\circ} 07^{\prime} 6^{\prime \prime} \mathrm{N}, \\
83^{\circ} 36^{\prime} 18^{\prime \prime} \mathrm{E}\end{array}$ & 3782 & 84.58 & 8.52 & - & 湖泥 & - & - \\
\hline 57 & $\mathrm{xz}-28$ & 吓嘎错 & $\begin{array}{l}32^{\circ} 16^{\prime} 15^{\prime \prime} \mathrm{N}, \\
83^{\circ} 50^{\prime} 22^{\prime \prime} \mathrm{E}\end{array}$ & 4378 & 8.68 & 9.77 & - & 湖泥 & - & - \\
\hline 58 & $x z-29$ & & $\begin{array}{l}32^{\circ} 20^{\prime} 9^{\prime \prime} \mathrm{N}, \\
83^{\circ} 43^{\prime} 45^{\prime \prime} \mathrm{E}\end{array}$ & 4147 & 9.97 & 9.42 & 0.2 & 浅红褐色湖泥 & $1 / 1$ & 6 \\
\hline 59 & $\mathrm{xz}-30$ & & $\begin{array}{l}32^{\circ} 21^{\prime} 27^{\prime \prime} \mathrm{N}, \\
83^{\circ} 42^{\prime} 11^{\prime \prime} \mathrm{E}\end{array}$ & 4383 & 40.71 & 9.78 & - & 湖泥 & - & - \\
\hline 60 & $\mathrm{xz}-31$ & 物玛错 & $\begin{array}{l}32^{\circ} 26^{\prime} 26^{\prime \prime} \mathrm{N} \\
83^{\circ} 12^{\prime} 27^{\prime \prime} \mathrm{E}\end{array}$ & 4449 & 1.72 & 9.63 & 0.3 & 含水草湖泥 & $3 / 3$ & 155 \\
\hline
\end{tabular}




\begin{tabular}{|c|c|c|c|c|c|c|c|c|c|c|}
\hline \multirow[b]{2}{*}{ 序号 } & \multirow[b]{2}{*}{ 样号 } & \multirow[b]{2}{*}{ 采样点 } & \multirow[b]{2}{*}{ 位置 } & \multirow{2}{*}{$\begin{array}{c}\text { 海拔/ } \\
\mathrm{m}\end{array}$} & \multirow{2}{*}{$\begin{array}{c}\text { 盐度/ } \\
\% 0\end{array}$} & \multirow[b]{2}{*}{$\mathrm{pH}$ 值 } & \multirow{2}{*}{$\begin{array}{l}\text { 采样点 } \\
\text { 水深 } / \mathrm{m}\end{array}$} & \multirow[b]{2}{*}{ 水体底质 } & \multicolumn{2}{|c|}{ 介形虫壳体 } \\
\hline & & & & & & & & & $\begin{array}{l}\text { 属/ } \\
\text { 种数 }\end{array}$ & $\begin{array}{l}\text { 总壳瓣数/ } \\
(\text { 枚/50 g) }\end{array}$ \\
\hline 61 & $\mathrm{xz}-32$ & 物玛错 & $\begin{array}{l}32^{\circ} 26^{\prime} 36^{\prime \prime} \mathrm{N}, \\
83^{\circ} 12^{\prime} 1^{\prime \prime} \mathrm{E}\end{array}$ & 4450 & 0.45 & 9.00 & 0.2 & 湖泥, 含水草 & - & - \\
\hline 62 & $x z-33$ & & $\begin{array}{l}32^{\circ} 26^{\prime} 34^{\prime \prime} \mathrm{N}, \\
83^{\circ} 11^{\prime} 56^{\prime \prime} \mathrm{E}\end{array}$ & 4465 & 0.68 & 9.03 & - & 湖泥, 含水草 & - & - \\
\hline 63 & $\mathrm{xz}-34$ & & $\begin{array}{l}32^{\circ} 26^{\prime} 31^{\prime \prime} \mathrm{N}, \\
83^{\circ} 11^{\prime} 48^{\prime \prime} \mathrm{E}\end{array}$ & 4453 & 5.64 & 9.49 & - & 湖泥 & - & - \\
\hline 64 & $\mathrm{xz}-35$ & & $\begin{array}{l}32^{\circ} 26^{\prime} 36^{\prime \prime} \mathrm{N}, \\
83^{\circ} 11^{\prime} 56^{\prime \prime} \mathrm{E}\end{array}$ & 4445 & 0.87 & 8.88 & - & 湖泥, 含水草 & - & - \\
\hline 65 & $x z-36$ & 别若则错 & $\begin{array}{l}32^{\circ} 25^{\prime} 27^{\prime \prime} \mathrm{N}, \\
83^{\circ} 0^{\prime} 28^{\prime \prime} \mathrm{E}\end{array}$ & 4433 & 2.16 & 9.71 & - & 湖泥 & - & - \\
\hline 66 & $x z-37$ & & $\begin{array}{l}32^{\circ} 24^{\prime} 44^{\prime \prime} \mathrm{N}, \\
82^{\circ} 58^{\prime} 39^{\prime \prime} \mathrm{E}\end{array}$ & 4418 & 28.65 & 9.26 & - & 砂砾底质 & $2 / 2$ & 2 \\
\hline 67 & $\mathrm{xz}-38$ & $\begin{array}{l}\text { 雄巴乡 } \\
\text { 小湖泊 }\end{array}$ & $\begin{array}{l}32^{\circ} 3^{\prime} 51^{\prime \prime} \mathrm{N}, \\
81^{\circ} 57^{\prime} 19^{\prime \prime} \mathrm{E}\end{array}$ & 4591 & 0.75 & 9.56 & - & 湖泥 & - & - \\
\hline 68 & $x z-39$ & $\begin{array}{l}\text { 日土 } \\
\text { 西湖泊 }\end{array}$ & $\begin{array}{l}33^{\circ} 28^{\prime} 47^{\prime \prime} \mathrm{N}, \\
80^{\circ} 17^{\prime} 7^{\prime \prime} \mathrm{E}\end{array}$ & 4300 & 41.50 & 9.61 & - & 含泥砂砾 & $2 / 2$ & 10 \\
\hline 69 & $\mathrm{xz}-40$ & & $\begin{array}{l}33^{\circ} 29^{\prime} 56^{\prime \prime} \mathrm{N}, \\
80^{\circ} 17^{\prime} 9^{\prime \prime} \mathrm{E}\end{array}$ & 4301 & 41.26 & 9.60 & - & 含盐湖泥 & - & - \\
\hline 70 & $x z-41$ & $\begin{array}{l}\text { 日土西 } \\
\text { 浅水坑 }\end{array}$ & $\begin{array}{l}33^{\circ} 31^{\prime} 51^{\prime \prime} \mathrm{N}, \\
80^{\circ} 15^{\prime} 20^{\prime \prime} \mathrm{E}\end{array}$ & 4308 & 66.15 & 8.13 & 0.2 & 含泥细砂 & $4 / 5$ & 121 \\
\hline 71 & $x z-42$ & $\begin{array}{l}\text { 日土西 } \\
\text { 湖泊 }\end{array}$ & $\begin{array}{l}33^{\circ} 33^{\prime} 11^{\prime \prime} \mathrm{N}, \\
80^{\circ} 9^{\prime} 9^{\prime \prime} \mathrm{E}\end{array}$ & 4309 & 122.70 & 8.22 & - & 黑色含粉细砂湖泥 & $4 / 4$ & 10 \\
\hline 72 & $x z-43$ & & $\begin{array}{l}33^{\circ} 34^{\prime} 3^{\prime \prime} \mathrm{N}, \\
79^{\circ} 56^{\prime} 58^{\prime \prime} \mathrm{E}\end{array}$ & 4277 & 0.76 & 8.64 & - & 黑色含泥粉砂, 有水草 & $7 / 11$ & 467 \\
\hline 73 & $x z-44$ & $\begin{array}{l}\text { 班公错 } \\
\text { 西北岸 }\end{array}$ & $\begin{array}{l}33^{\circ} 32^{\prime} 29^{\prime \prime} \mathrm{N}, \\
79^{\circ} 54^{\prime} 56^{\prime \prime} \mathrm{E}\end{array}$ & 4265 & 0.75 & 9.03 & - & 含泥砂砾, 有水草 & $5 / 6$ & 21 \\
\hline 74 & $\mathrm{xz}-45$ & $\begin{array}{c}\text { 班公错 } \\
\text { 东南岸 } \\
\text { 湿地 }\end{array}$ & $\begin{array}{l}33^{\circ} 26^{\prime} 16^{\prime \prime} \mathrm{N}, \\
79^{\circ} 45^{\prime} 52^{\prime \prime} \mathrm{E}\end{array}$ & 4271 & 2.25 & 9.70 & - & 深青灰色湖泥, 有水草 & $6 / 9$ & 227 \\
\hline 75 & $x z-46$ & $\begin{array}{c}\text { 日土 } \\
\text { 西湖泊 }\end{array}$ & $\begin{array}{l}33^{\circ} 6^{\prime} 14^{\prime \prime} \mathrm{N}, \\
80^{\circ} 22^{\prime} 8^{\prime \prime} \mathrm{E}\end{array}$ & 4358 & 2.33 & 10.14 & - & 黑色含泥粉细砂 & $2 / 2$ & 4 \\
\hline 76 & $x z-47$ & & $\begin{array}{l}33^{\circ} 6^{\prime} 56^{\prime \prime} \mathrm{N}, \\
80^{\circ} 14^{\prime} 38^{\prime \prime} \mathrm{E}\end{array}$ & 4365 & 1.33 & 9.48 & - & 湖泥, 含黑色水草 & - & - \\
\hline 77 & $\mathrm{xz}-48$ & & $\begin{array}{l}33^{\circ} 6^{\prime} 11^{\prime \prime} \mathrm{N}, \\
80^{\circ} 11^{\prime} 46^{\prime \prime} \mathrm{E}\end{array}$ & 4367 & 2.29 & 10.41 & - & 黑色含泥粉细砂 & $3 / 4$ & 73 \\
\hline 78 & $\mathrm{xz}-49$ & $\begin{array}{l}\text { 日土 } \\
\text { 西河流 }\end{array}$ & $\begin{array}{l}33^{\circ} 1^{\prime} 22^{\prime \prime} \mathrm{N}, \\
79^{\circ} 48^{\prime} 28^{\prime \prime} \mathrm{E}\end{array}$ & 4391 & 2.26 & 9.56 & 0.2 & 湖泥, 有水草 & $2 / 2$ & 6 \\
\hline
\end{tabular}

